\title{
ASSESSMENT OF GINGIVAL RECESSION AMONG ADOLESCENT OF JAMSHORO CITY.
}

1. MSc Operative Dentistry Associate Professor Department of Oral Biology Institute of Dentistry LUMHS Jamshoro

2. MSc Trainee Department of Community Dentistry Institute of Dentistry LUMHS Jamshoro

3. BDS, FCPS Maxillary Surgery Associate Professor Department of Oral and Maxillofacial Surgery Institute of Dentistry LUMHS Jamshoro

4. MSc Trainee Department of Community Dentistry Institute of Dentistry LUMHS Jamshoro

Correspondence Address: Dr. Maryam Panhwar

Department of Community Dentistry Institute of Dentistry,LUMHS Jamshoro dr.maryam.2101@gmail.com

Article received on:

29/11/2018

Accepted for publication:

22/03/2019

Received after proof reading: 28/08/2019

\begin{abstract}
Munir Ahmed Banglani' ${ }^{1}$, Maryam Panhwar ${ }^{2}$, Suneel Kumar Punjabi ${ }^{3}$, Komal Memon ${ }^{4}$
\end{abstract}
\begin{abstract}
Objectives: The aim of study to determine the occurrence of gingival recession in younger population of Jamshoro, also to identify its common cause, so that we can able to establish preventive measures. Study Design: Cross-sectional. Setting: Dental OPD at Liaquat University of Medical Health Sciences Jamshoro. Period: 4 months from May, 2017 to October 2017. Material and Methods: Study was done on (300) patients, between 18 to 30 years, before selection, they were examined, only those selected, who have gingival recession, this was done by Miller's Classification, data was obtained by a questionnaire along with the clinical examination. Perform was consists of detailed information of habits and brushing method, scores were given for presence of gingival recession, using Miller's classification. Identification of faulty brushing technique was done by clinical examining. After the completion, all of them were also given suitable treatments also oral hygiene instructions. Results: Mean age of the was $21.09 \pm 6.178$. Scores of recessions was done according to the classification of Miller, revealed that Class I were the commonest showed $78 \%$, followed by Class II $16 \%$, Class III $4.6 \%$ and Class IV 1.4\%.Regarding brushing method (horizontal method, medium tooth brush) Statistical analysis revealed that the correlation between both toothbrush type and brushing method and gingival recession were statistically significant $(P<0.001)$. Conclusion: The accumulation of plaque and wrong brushing method were the commonest causes of recession, educational program for oral health care should be done at community level to reduce its risk. The information from study would help us to made to prevent strategies and therapeutic methods.
\end{abstract}

Key words: $\quad$ Assessment, Adolescent, Faulty Brushing, Gingival Recession.

Article Citation: Banglani MA, Panhwar M, Punjabi SK, Memon K. Assessment of gingival recession among adolescent of Jamshoro city. Professional Med J 2019; 26(9):1427-1433. DOI: 10.29309/TPMJ/2019.26.09.1357

\section{INTRODUCTION}

The most commonest and unwanted situation occurs at gingiva known as gingival recession, which is affecting about more than about $50 \%$ of significant ratio of the population. ${ }^{1}$ It is basically a pathological condition in which gingiva moves apically and exposes root surface of tooth in oral cavity, exposed root portion is prone to abrasion on brushing, this may cause sensitivity on hot and cold substances and chances of root caries increases that ultimately leads to tooth loss secondary to clinical attachment loss of gingiva if left untreated. ${ }^{2}$

Gingival recession might apparently so unaesthetic state of condition, especially if a person is younger one, and if the site of recession is located at the front tooth of the mouth, it will be so embracing situation for a person when he/ she smiles or speaks to anyone. Some author saying, if an irregular gum line happens it can be results in distracting and even compromises an attractive smile. ${ }^{3}$

One of the study done earlier, by Joshipura et all ${ }^{4}$ showed that gingival recession is one of the complex disease and which having multifactorial etiology. This is because it can be occurred amongst young people as well old, and also occurs in people with having good oral hygiene and also having bad oral hygiene this suggests that proper diagnosis and treatment should be provided to the patients at risk.

According to careful literature review $^{5}$, we concluded that the risk factors for development of 
gingival recession may be due to improper tooth brushing technique, or given trauma to soft tissues by toothbrush, tooth which are at mal position, are at risk of destructive periodontal diseases including alveolar bone dehiscence destructive periodontal diseases, alveolar bone dehiscence, high muscular attachment such as frenal attachment which pulls soft tissues at gingiva, thin and delicate marginal tissue which covers the non-vascularized root surface, occlusal traumas, lip piercing and other different iatrogenic factors related to conservative, orthodontic, prosthetics treatments and smoking. ${ }^{6}$

Even though some of the clinical proof given by Addy and Hunter $2002^{7}$, suggested the use of a manual and electronic toothbrushes had report and observed the development of gingival recession followed by tooth brushing method. Although most frequently occurring condition on the gingiva is gingival recession. Still limited studies had been done on the prevalence and etiology of gingival recession among young adults had been carried out in our country Pakistan. Therefore, it is very important to collect proper and detailed information, to assess the tendency, and also to identify its main etiological factors which are associated with this, so that we can be able to establish preventive measures and treatment plans for young people so that younger adults can get rid of this undesirable condition.

Hence, the aim of our present study was to determine the occurrence of gingival recession among younger population of Jamshoro city and also to identify the most common factors associated with the cause of gingival recession among individuals aged between to 18 to 30 years.

\section{MATERIALS AND METHODS}

Cross-sectional study was done on three hundred (300) adolescent male and female patients who attended Dental OPD, at Liaquat University of Medical and Health science Jamshoro.

From May, 2017 to October 2017, all of the young patients, who comes to dental OPD, were examined clinically by chief investigator, we selected only those participants for our study who had one or more gingival recession this was done by help of Miller's Classification for Gingival Recession, aged between 18 to 30 years, had 20 teeth after selection of the participates for study, informed verbal and written consent was taken from each of participants, data was obtained from each individual who participated in the study questionnaire was filled and clinical examination principal investigator. It was consisting of detailed information of particulate's personal habits and brushing method, each of our study participants for scoring regarding gingival recession, Miller's classification was used, with the help of William's periodontal probe and CPI probe. Identification of faulty tooth brushing technique was done by clinical examination, the presence of cervical abrasion on the cervical area of facial surface of the tooth surface of the tooth, any of the sensitivity on teeth were ask as evaluated as these problems were associated by overzealous brushing, participants were asked how long they brush their teeth normally. Clinical assessment done for all of the surfaces of the teeth for any accumulation of calculus and food debris, participants were asked about the condition of toothbrush. if bristles of any of the participant's brush had been flared been flared out to the sides of the brush, it means the patient is applying too much pressure. Also asked about the frequency of the tooth brushing to know the link with gingival recession. People who brush their teeth immediately after consumption of acidic diet are at high risk of developing erosion which appear as a polished surface free from calculus deposition. ${ }^{8}$ To confirm the adequacy of the width of the attached gingiva Tension test was carried out. ${ }^{9}$ The tension test applied to the lip in the outward, downward/ upward, and lateral directions. And gingival margin is observed. Any type of movement of the free gingiva is recorded as positive response to the tension test. Trauma by faulty occlusion was evaluated by examining the mobility of each tooth. ${ }^{10}$

After the completion of clinical tests and history of our study participants, all of them were given suitable treatment at different departments and also oral hygiene care instructions were given to them. 


\section{Data Analysis}

The data obtained were subjected to statistical analysis using Chi-square test and students unpaired t-test. The result was tabulated using SPSS version 16.0 value less than $5 \%(p<0.05)$ was considered to be statistically significant.

\section{RESULT}

Gingival recession was observed in 300 patients. All subjects between 18 to 30 years. The mean age of patients was $21.09 \pm 6.178$ as shown in (Table-I). The females were affected more in comparison with male, as shown in the (TableII), the ratio of gender distribution is shown in Figure-1, Examination of the gingival recession was done according to the classification of Miller's, which revealed that Class I recessions were the most prevalent showed $78 \%$, followed by Class II recessions 16\%, Class III $4.6 \%$ and Class IV recessions 1.4\% (Table-III).

we also found that most commonly affected teeth were mandibular incisors with gingival recession $45 \%$ and followed by maxillary first molars also showed gingival recession $10 \%$ shown in (Figure-2).

Patients were also asked about cleaning habits for their teeth by using toothbrush. The percentage of cleaning methods were shown in (Figure-3).

Regarding tooth brush and brushing method (horizontal method, medium textured tooth brush) our Statistical analysis revealed that the correlation between both toothbrush type and brushing method and gingival recession were statistically significant $(P<0.001)$ the correlation was statistically significant $(P=0.001)$, shown in (Table-IV).

Dental plaque biofilm along with gingival inflammation appeared to be the most frequent precipitating etiological factors $44.1 \%$, followed by faulty tooth brushing method $42.7 \%$ shown in (Figure-4).

\begin{tabular}{|c|c|c|c|}
\hline \multicolumn{2}{|l|}{ Mean } & \multicolumn{2}{|r|}{21.09} \\
\hline \multicolumn{2}{|l|}{ Std Deviation } & \multicolumn{2}{|r|}{6.178} \\
\hline \multicolumn{2}{|l|}{ Range } & \multicolumn{2}{|r|}{22} \\
\hline \multicolumn{2}{|l|}{ Minimum } & \multicolumn{2}{|r|}{12} \\
\hline \multicolumn{2}{|l|}{ Maximum } & \multicolumn{2}{|r|}{26} \\
\hline \multicolumn{4}{|c|}{ Table-I. Age of patients statistics } \\
\hline & \multicolumn{2}{|c|}{ Frequency } & Percent \\
\hline Male & \multicolumn{2}{|c|}{170} & 56.7 \\
\hline Female & \multicolumn{2}{|c|}{130} & 43.3 \\
\hline Total & \multicolumn{2}{|c|}{300} & 100.0 \\
\hline \multicolumn{4}{|c|}{ Table-II. Male and female distribution } \\
\hline $\begin{array}{c}\text { Miller's } \\
\text { Classification }\end{array}$ & $\%$ & Mean & Std. Deviation \\
\hline CLASS I & 78 & 0.749 & 0.3367 \\
\hline CLASS II & 16 & 1.209 & 0.3454 \\
\hline CLASS III & 4.6 & 0.494 & 0.4629 \\
\hline CLASS IV & 1.4 & 0.907 & 0.4749 \\
\hline
\end{tabular}

\section{Ratio of Gender Distribution}

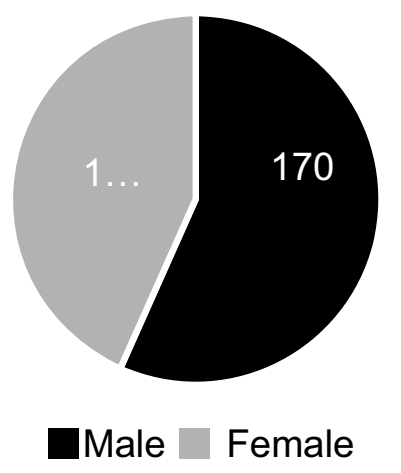

Figure-1. Ratio of gender distribution

\begin{tabular}{|l|c|c|c|c|}
\hline $\begin{array}{c}\text { Tooth Brushing } \\
\text { Method }\end{array}$ & N & Mean & $\begin{array}{c}\text { Std. } \\
\text { Deviation }\end{array}$ & P-Value \\
\hline Horizontal Brushing & 99 & 2.230 & 1.3894 & \\
\hline Vertical Brushing & 99 & 1.988 & 0.5819 & 0.001 \\
\hline Circular Brushing & 91 & 1.482 & 0.3836 & \\
\hline Free style & 280 & 1.900 & 0.9419 & \\
\cline { 1 - 2 } & \multicolumn{3}{|c|}{ Table-IV. Relation of brushing } \\
\hline
\end{tabular}




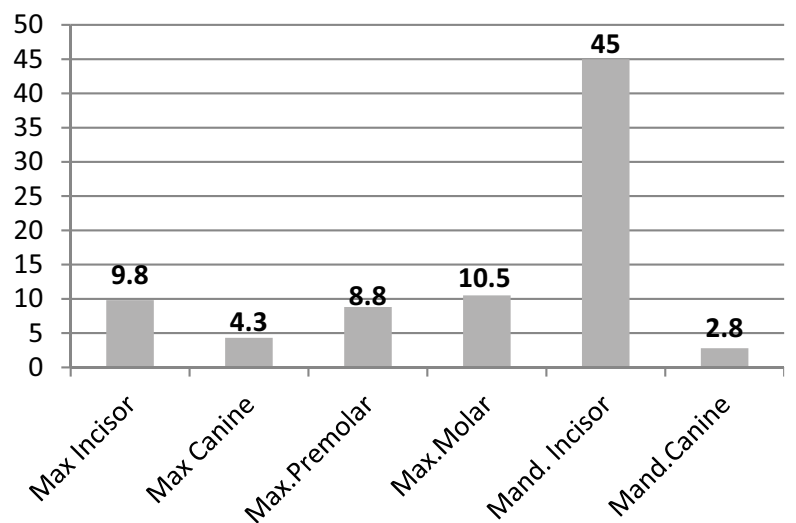

Figure-2. Percentage \% of GR (gingival recession) according to teeth

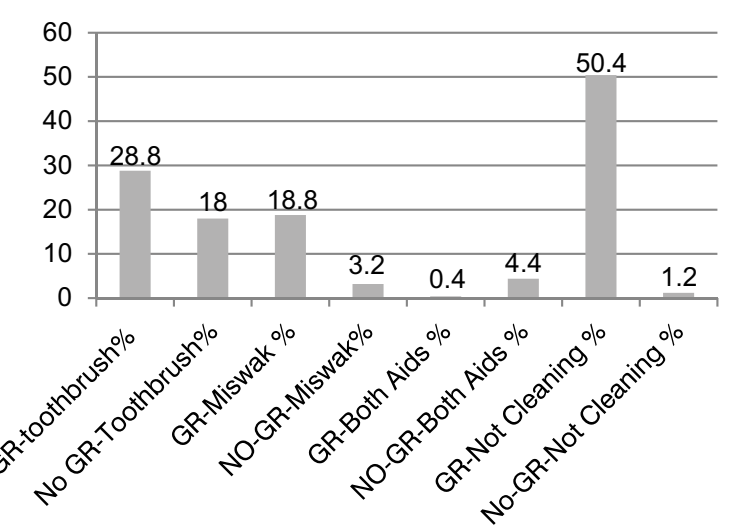

Figure-3. Percentage \% of cleaning method

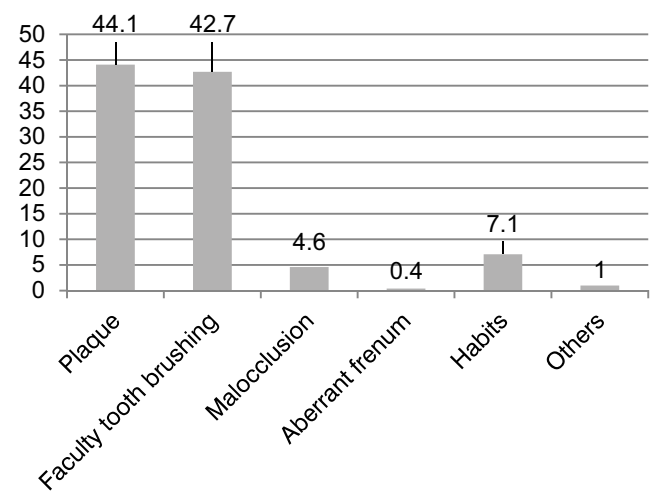

Figure-4. Etiology factors of GR (gingival recession) in percentage

\section{DISCUSSION}

According to the literature review gingival recession can be localized affecting single tooth in oral cavity or it could be generalized form (like many of teeth affecting throughout the oral cavity) it is described as a pathological as well as an unwanted condition for all individuals, if younger population were affected by this annoying situation they might concerns more by the presence of this disturbing and un esthetic state. In past many of the different studies has been done to investigate associated factors of Gingival Recession. ${ }^{1,11}$, In our study we will chose younger population of Jamshoro city to investigate most common causes of gingival recession so that we can be to do early treatments for this problematic condition.

By this study we also found that every individual should have knowledge about the main etiology, and also different factors associating with gingival recession so that appropriate treatments should be done by dentist and also patients should take care of their own oral habits, such of these simple treatments and life style modifications typically result in esthetic improvement of a patient, decreases tooth sensitivity and also limits the risk of developing root caries.

Total 300 individuals participated in our study, all of them showed gingival recession with different etiology. Similar results were also seen in earlier studies. ${ }^{12-14}$ Many studies have been done in different parts of the world on the prevalence of gingival recession their results revealed that approximately more than $50 \%$ of the population has high prevalence of gingival recession among younger population. ${ }^{11,15-17}$ Surveys also exposed that the presence and level of gingival recession will be increased with increasing age. ${ }^{11,18}$

In our study assess main etiological factors associated with gingival recession mostly in young individuals, our results from different clinical examinations and history we found that the presence of gingival recession in younger population of Jamshoro city may interconnected to traumatic or faulty(aggressive tooth brushing) mal-positioned teeth were also showed recession, and tobacco consumer also indicated this condition, it has given us clue that recession can might be a multi-factorial disease, in which one type is being related with anatomical factors and on the other hand another type is with physiological or may be pathological factors, 
another study also showed same results like ours which was done in college of Dentistry, KKU, Abba city of Saudi Arabia. ${ }^{1}$

We also found that most frequent occurrence of gingival recession on buccal surfaces of the teeth, we selected only young individuals for our study and more than $65 \%$ of these young individuals existing recessions was smaller than $3 \mathrm{~mm}$.

If we talk about the main precipitating factors for gingival recession which were already described in different form of literatures is the bacterial origin plaque $^{2,12,19}$, another can be mechanical trauma results in related to hard-bristled tooth brushing methods ${ }^{20,21}$, and also frequency of faulty tooth brushing practices ${ }^{22}$, orthodontic treatment therapies ${ }^{23}$ different chemical traumas, primarily habit of smoking.

In our study we used Miller's classification to assess severity of gingival recession as by estimation for extension of an exposed root surface, by doing this we also found that Miller's class I type of recession was more common among young population. In comparison with other studies, findings of this study were class I followed by class II according to Miller's. After care-full review of various studies, this study concluded favorable prognosis for class I and poor prognosis for class III and IV. ${ }^{24}$

Results ofthisstudyshowedthatlower (mandibular) teeth were mostly commonly affected teeth by Gingival Recession, this finding is in contrast with previous studies. ${ }^{26}$ The reason behind its most usually occurrence on lower mandibular teeth is due to characteristics feature of its mucosa that is keratinized mucosa, which is more wider and also more thicker at the maxilla region as compare to mandibular anterior mucosa ${ }^{27}$, The areas which were lacking of keratinized mucosa, particularly in thickness, have been confirmed to be more prone in occurrence of gingival recession, This is mostly due to having smaller amount of connective tissue available on the specific area, which will further results to localized inflammatory reactions produced by different processes and able to affect the whole of the tissue extension, which eventually results in gingival recession. ${ }^{27-29}$ No any kind of differences were observed in the occurrence of gingival recession at the right side in compare with left side of the mouth in this study.

In this study we also found that dental plaque is also one of the most common cause for gingival recession in patient having poor oral hygiene, and faulty tooth brushing technique was the second most common cause of gingival recession. $(44.0 \%)(p<0.001)$.

In the present study, we also ask about tooth brushing methods done by patients, and we also correct them by giving demos on it. We found that patients who used, method had more gingival recession than patients who were using vertical or circular method (11.78\%). Vigorous use of hard textured tooth brush with horizontal method may lead to ulcerations, abrasions and recession of gingiva. ${ }^{30-32}$ With this study it is now also confirmed that individuals with standard or good maintained oral hygiene can might develop gingival recession, we begin dentist should need to give instructions on proper usage of tooth brushing methods and also other available aids to maintain their own oral hygiene. With the help of systematic review form different researches, we also concluded that tooth brushing is major factor that has been in associated in the development and also progression towards gingival recession which also co-related with frequency, duration and brushing technique. ${ }^{30}$

\section{CONCLUSION}

Our findings from this research proved that accumulation of plaque biofilm and wrong brushing method were the commonest causes of gingival recession occurrence among adolescents population of Jamshoro, we also concluded that gingival recession is mostly multifactorial, along with avoiding oral hygiene care, we recommend different educational programs should be arranged at different community levels to reduce this developing problem among adolescent population. The information that we collected from our study would probably help us to focus on preventive strategies as well as therapeutic methods. 


\section{CONFLICT OF INTEREST}

No any conflict of interest regarding this study. Copyright $(22$ Mar, 2019.

\section{REFERENCES}

1. Eid HE. Prevalence of anterior gingival recession and related factors among Saudi adolescent males in Abha City, Aseer Region, Saudi Arabia. J Dent Res Rev. 2014; 1(1):18.

2. Chrysanthakopoulos NA. Aetiology and severity of gingival recession in an adult population sample in Greece. Dent Res J. 2011; 8(2):64.

3. Kamak G, Kamak H, Keklik H, Gurel HG. The effect of changes in lower incisor inclination on gingival recession. The Scientific World Journal. 2015;2015.

4. Joshipura K, Wand H, Merchant A, Rimm E. Periodontal disease and biomarkers related to cardiovascular disease. J Dent Rev. 2004; 83(2):151-5.

5. Heasman PA, Holliday R, Bryant A, Preshaw PM. Evidence for the occurrence of gingival recession and non $\square$ carious cervical lesions as a consequence of traumatic toothbrushing. J clin Perio. 2015; 42:S237-S55.

6. Heasman PA, Holliday R, Bryant A, Preshaw PM. Evidence for the occurrence of gingival recession and non $\square$ carious cervical lesions as a consequence of traumatic toothbrushing. J clin Perio. 2015; 42(S16).

7. Hunter M, Addy M, Pickles M, Joiner A. The role of toothpastes and toothbrushes in the aetiology of tooth wear. Int Dent J. 2002; 52(S5):399-405.

8. Gillette WB, Van House RL. III effects of improper oral hygiene procedures. J American Dent Asso. 1980; 101(3):476-81.

9. Kisch J, Badersten A, Egelberg J. Longitudinal observation of "unattached," mobile gingival areas. J Cli Perio. 1986; 13(2):131-4.

10. Dodwad V. Aetiology and severity of gingival recession among young individuals in belgaum district in India. Annal Dent Univ Malaya. 2001; 8:1-6.

11. Mythri S, Arunkumar SM, Hegde S, Rajesh SK, Munaz $M$, Ashwin $D$. Etiology and occurrence of gingival recession-An epidemiological study. Journal of Indian Soc Perio. 2015; 19(6):671.

12. Mumghamba E, Honkala S, Honkala E, Manji K. Gingival recession, oral hygiene and associated factors among Tanzanian women. East African Med J. 2009; 86(3):125-32.
13. Grover H, Aggarwal N. Observational study on the association between gingival recession and other clinical variables in an adult population In India. Indian J Dent Sci. 2012; 4(1).

14. Kassab MM, Cohen RE. The etiology and prevalence of gingival recession. J American Dent Asso. 2003; 134(2):220-5.

15. Toker $\mathrm{H}, \mathrm{Ozdemir} \mathrm{H}$. Gingival recession: epidemiology and risk indicators in a university dental hospital in Turkey. Int J Dent hyg. 2009; 7(2):115-20.

16. Ainamo J, Paloheimo L, Nordblad A, Murtomaa H. Gingival recession in schoolchildren at 7, 12 and 17 years of age in Espoo, Finland. Comm Dent Oral Epid. 1986; 14(5):283-6.

17. Bindu R, Cheru T. Prevalence and etiology of gingival recession-An epidemiol stu. ISP Bull. 1992; 16:4-8.

18. Gorman WJ. Prevalence and etiology of gingival recession. J. Perio. 1967; 38(4):316-22.

19. Lafzi A, Abolfazli N, Eskandari A. Assessment of the etiologic factors of gingival recession in a group of patients in Northwest Iran. J Den Res, Dent Clin, Dent Pros. 2009; 3(3):90.

20. Khocht A, Simon G, Person P, Denepitiya JL. Gingival recession in relation to history of hard toothbrush use. J. Perio. 1993; 64(9):900-5.

21. Checchi L, Daprile G, Gatto MRA, Pelliccioni GA. Gingival recession and toothbrushing in an Italian School of Dentistry: A pilot study. J. Cli perio. 1999; 26(5):276-80.

22. Vehkalahti $M$. Occurrence of gingival recession in adults. J. Perio. 1989; 60(11):599-603.

23. Steiner GG, Pearson J, Ainamo J. Changes of the marginal periodontium as a result of labial tooth movement in monkeys. J Perio. 1981; 52(6):314-20.

24. Marini MG, Greghi SLA, Passanezi E, Sant'Ana ACP. Gingival recession: prevalence, extension and severity in adults. J. App Oral Sci. 2004; 12(3):250-5.

25. Almeida ALPFd, Madeira LC, Freitas KCd, Greghi SLA, Pegoraro LF. Cross-sectional evaluation of the presence of gingival recession in individuals with cleft lip and palate. J. Perio. 2007; 78(1):29-36.

26. Freedman AL, Salkin LM, Stein MD, Green K. A 10year longitudinal study of untreated mucogingival defects. J. Perio. 1992; 63(2):71-2. 
27. Kennedy JE, Bird WC, Palcanis KG, Dorfman HS. A longitudinal evaluation of varying widths of attached gingiva. J. cli perio. 1985; 12(8):667-75.

28. Ruf S, Hansen K, Pancherz H. Does orthodontic proclination of lower incisors in children and adolescents cause gingival recession? American J. Orth and Dent Ortho. 1998; 114(1):100-6.

29. Roberts-Harry E, Clerehugh V. Subgingival calculus: where are we now? A comparative review. J. Dent. 2000; 28(2):93-102.
30. Rajapakse PS, McCracken GI, Gwynnett E, Steen ND, Guentsch A, Heasman PA. Does tooth brushing influence the development and progression of non $\square$ inflammatory gingival recession? A systematic review. J. Cli perio. 2007; 34(12):1046-61.

31. Bergström J, Lavstedt S. An epidemiologic approach to toothbrushing and dental abrasion. Comm Dent Oral Epid. 1979; 7(1):57-64.

32. Faisal A, Jari N, Deemah A, Redwan S, Gogandy $B$, Othman $H$. Tooth brushing behavior and its prevalence versus Miswak usage among the dental students of the faculty of dentistry at King Abdulaziz University. Int Dent J Stu R. 2015; 2 (1):57-64.

\begin{tabular}{|c|c|c|c|}
\hline \multicolumn{4}{|c|}{ AUTHORSHIP AND CONTRIBUTION DECLARATION } \\
\hline Sr. \# & Author-s Full Name & Contribution to the paper & Author's Signature \\
\hline 2 & $\begin{array}{l}\text { Munir Ahmed Banglani } \\
\text { Maryam Panhwar } \\
\text { Suneel Kumar Punjabi } \\
\text { Komal Memon }\end{array}$ & $\begin{array}{l}\text { Supervisor / Introduction. } \\
\text { Results and decisions writing. } \\
\text { Literature review. } \\
\text { Data collection. }\end{array}$ & Romal \\
\hline
\end{tabular}

